\title{
Effect of Feeding Regime on Biological and Biochemical Parameters in Ayu
}

\author{
Heisuke Nakagawa, Tetsuya Umino, and Hideyuki Mizogami \\ Faculty of Applied Biological Science, Hiroshima University, Higashi-hiroshima 739-8528, Japan \\ (Received September 4, 1998)
}

To find the adequate feeding condition in ayu Plecoglossus altivelis culture, fish averaging $5.1 \mathrm{~g}$ in body weight were reared on different feeding regimes. Group I and III were satiated two and four times daily, respectively. Group II was fed a diet equivalent to $60 \%$ of the diet fed to group III with four daily feedings. The effects were assessed by growth, anatomical measurements, and biochemical parameters.

Growth and feed conversion efficiency were not significantly different among the three groups. While stomach volume was not significantly different, the intestine was longer in the fish fed four times daily with restricted diets (group II). The serum glucose level increased with feeding frequency. Hepatic enzymes, glucose-6-phosphatase and alanine aminoacyl transaminase, which are associated with glycolysis and amino acid turnover, were higher in group II.

Following the feeding experiment, the fish were kept without feeding for 23 days. Mortality and body weight loss were lower in the group reared on four daily feeding with restricted diets. Feeding four times daily with restricted rations resulted in high growth performance and normal physiological conditions.

Key words: ayu, feeding regime, intestine length, growth, metabolism, starvation test

The ayu Plecoglossus altivelis are widely cultured and one of the most important freshwater fish in Japan. To improve the quality of cultured ayu, we conducted a series of studies on food additives, ${ }^{1)}$ feeding regime, ${ }^{2)}$ and water velocity. ${ }^{3)}$ Feeding frequency and ration size highly influence growth performance and metabolism in fish. Ayu culturists actually feed to satiation three or four times daily with automatic feeders. Reducing feed expenses is one of the important factors in fish culture to increase feed utilization and to reduce wasted feed. The importance of feeding regimen such as feeding frequency and ration in fish culture has been described in various fishes. ${ }^{2,4-13)}$

Previous studies showed that feeding frequency affects growth performance and lipid metabolism in ayu ${ }^{2)}$ red sea bream Pagrus major, ${ }^{4)}$ and red spotted grouper Epinepherus akaara. ${ }^{5)}$ Adequate feeding frequency might be dependent on the fish species. Feeding behavior in the natural environment might be reflected in the digestive mechanisms and the feeding regime of cultured fish.

Based on the findings that four daily feedings yield high growth performance with low lipid accumulation, ${ }^{2)}$ a further study was conducted to obtain beneficial feeding conditions in terms of some physiological parameters.

\section{Materials and Methods}

\section{Fish and Rearing Conditions}

Ayu eggs were spawned at the Hiroshima City Marine Products Promotion Center. Larvae were reared for 120 days at the Ohta-gawa Fisherman's Association prior to being transported to Hiroshima University. Fish averaging $7.0 \mathrm{~cm}$ in total length and $5.1 \mathrm{~g}$ in body weight were divided into six outdoor concrete ponds $(1.0 \times 2.1 \times 0.6 \mathrm{~m}$ depth). Duplicate treatments were performed on 140 fish each, for three feeding regimes as follows: two satiation feedings per day at 9:30 and 17:00 (group I) and four satiation feedings per day at 9:00, 12:00, 15:00 and 18:00 (group III). Group II was fed four times daily with diet equivalent to $60 \%$ of the amount fed to group III, at 9:00, 12:00, 15:00 and 18:00 (group II). Fish were fed to apparent satiation with a dry composed diet (crumble diet, Yeaster Co. Ltd.) supplemented with $4 \%$ Alaskan pollack liver oil (Riken Vitamine Co. Ltd.), and the amounts of feed provided were recorded. Hand-feeding was carried out to encourage the fish to feed on the surface and feeding was usually of a 15 -minute duration to minimize wastage. The proximate composition of the diet was as follows: moisture $9.9 \%$, ash $8.7 \%$, crude protein $44.1 \%$, and lipid $9.3 \%$. The feeding was conducted over a period of 64 days (30 May-1 August) after acclimation for seven days. Water temperature ranged between 17.0 and $27.0^{\circ} \mathrm{C}$. Water flow rates to rearing ponds were maintained at 6.2 $l /$ min. After the feeding experiment, the fish were kept without feeding for an additional 23 days; the water temperature ranged between 24.6 and $27.8^{\circ} \mathrm{C}$.

\section{Biological Measurements}

At the end of the feeding experiment, fish were counted and weighed after 48-hour fasting. Fish sampled at random from each pond were used for morphological and anatomical measurements. Whole muscle (fillet), liver, intraperitoneal adipose tissue, stomach volume, and intestine length were measured. Stomach volume was measured according to the Kubo method. ${ }^{14)}$ Muscle ratio, hepatosomatic index (HIS), intraperitoneal fat body ratio (IPF ratio), relative stomach volume (RSV), and relative intestine length (RIL) were calculated from the following equations:

Muscle ratio $(\%)=($ muscle $w e i g h t /$ body weight $) \times 100$, 
HIS $(\%)=($ liver weight $/$ body weight $) \times 100$, IPF ratio (\%)

$=$ (intraperitoneal fat body weight/body weight $) \times 100$, RSV (\%) $=($ stomach volume $(\mathrm{g}) /$ body weight $(\mathrm{g})) \times 100$, and

RIL = intestine length/body length.

\section{Blood and Serum Properties}

The blood samples were drawn from the casual aorta using a syringe, and the hematcrit values were determined. The serum was submitted for analyses for protein (Biuret method), total lipid (Sulfo-phospho-vanillin method), nonesterified fatty acids (NEFA; NEFA C Test, Wako Co.), triglycerides (Triglyceride G Test, Wako Co.), phospholipids (Phospholipid B Test, Wako Co.), and glucose (Glucose CII Test, Wako Co.).

\section{Biochemical Mesurements}

Muscle, liver, and intraperitoneal fat body were frozen immediately after sacrifice and kept at $-80^{\circ} \mathrm{C}$ until analyses. Crude protein of muscle was measured using the Kjeldahl method. Lipid extracted by the Bligh and Dyer method $^{15)}$ was weighed.

The liver was homogenized with nine volumes of cold water for one minute. After centrifugation at 5,000 rpm $(2000 \mathrm{~g})$ for ten minutes at $0-4^{\circ} \mathrm{C}$, the supernatant was immediately submitted to enzyme analyses. Glucose-6-phosphatase (EC 3.1.3.9) and glucose-6-phosphatase (EC 1.1.1.49) were determined according to the method of Glock and McLean. ${ }^{16)}$ Pyruvate kinase (EC 2.7.1.40), NADP-malate dehydrogenase (EC 1.1.1.40), argrinase (EC 3.5.3.1), and alanine aminoacyl transaminase (EC 2.6.1.2) were determined according to the method of Moon and Johnston, ${ }^{17)}$ Ochoa, ${ }^{18)}$ Schwarz, ${ }^{19)}$ and Schimizu et al. ${ }^{20)}$ respectively. These enzyme activities were expressed as units per $\mathrm{g}$ liver.

\section{Statistical Analysis}

Data were analyzed for significance using one-way ANOVA and Scheffe's multiple range test.

\section{Result}

Groups I and III were satiated with the composed diet two and four times daily, respectively. The amount of the diet fed to group II was equivalent to $60 \%$ of the total diet fed to group III. The fish of all groups ate more actively at 9:00 and 18:00 rather than during the daytime. The amount of diet given to satiate four times daily was higher than that to satiate twice daily. However, the difference in rations did not significantly affect total biomass production and feed utilization. The fish fed four times with the restricted diet tended to display slightly lower biomass production and higher feed utilization (Table 1). Variability in fish size occurred even in fully fed groups.

Table 2 shows anatomical parameters of fish reared with different rations. Fish size was biggest in group III in response to rations. However, variation of the fish weight
Table 1. Effect of feeding regime on growth and feed utilization

\begin{tabular}{lccc}
\hline & \multicolumn{3}{c}{ Experimental group } \\
\cline { 2 - 4 } & I & II & III \\
\hline Daily feeding frequency (times) & 2 & 4 & 4 \\
Feeding condition & Satiated & Restricted & Satiated \\
Total diet fed (kg) & 8.30 & 7.38 & 12.21 \\
\hline Mortality (\%) & 9.6 & 13.2 & 13.6 \\
Biomass production $(\mathrm{kg})$ & 5.37 & 4.86 & 7.34 \\
Feed conversion efficiency $(\%)$ & 77.1 & 81.8 & 68.8 \\
Protein efficiency ratio*1 & 1.75 & 1.86 & 1.56 \\
Protein deposited $(\%)^{* 2}$ & 5.73 & 6.62 & 5.34 \\
\hline
\end{tabular}

Mean values from duplicate tanks containing 140 fish.

${ }^{*}$ Body weight gain/protein fed.

*2 (Muscle protein gain/protein fed) $\times 100$.

Table 2. Effect of feeding regime on anatomical parameters

\begin{tabular}{|c|c|c|c|c|}
\hline & & \multicolumn{3}{|c|}{ Experimental group } \\
\hline & & I & II & III \\
\hline \multirow[t]{2}{*}{ Body length $(\mathrm{cm})$} & Initial & $7.1 \pm 0.4$ & $7.0 \pm 0.4$ & $6.9 \pm 0.7$ \\
\hline & Final & $12.7 \pm 1.1^{\mathrm{a}, \mathrm{b}}$ & $12.3 \pm 0.7^{\mathrm{a}}$ & $13.4 \pm 1.5^{b}$ \\
\hline \multirow[t]{2}{*}{ Body weight (g) } & Initial & $5.4 \pm 0.9$ & $5.1 \pm 0.8$ & $4.8 \pm 1.2$ \\
\hline & Final & $30.3 \pm 8.2^{\mathrm{a}}$ & $28.2 \pm 4.9^{\mathrm{a}}$ & $37.0 \pm 12.1^{b}$ \\
\hline \multicolumn{2}{|l|}{ Muscle ratio (\%) } & $47.9 \pm 3.4$ & $47.5 \pm 4.2$ & $48.6 \pm 4.9$ \\
\hline \multicolumn{2}{|c|}{ Hepatosomatic index $(\%)$} & $1.22 \pm 0.18^{\mathrm{a}}$ & $1.07 \pm 0.21^{b}$ & $1.23 \pm 0.14^{\mathrm{a}}$ \\
\hline \multicolumn{2}{|l|}{ IPF ratio $(\%)^{*}$} & $4.32 \pm 1.21$ & $4.29 \pm 1.06$ & $4.92 \pm 1.93$ \\
\hline \multicolumn{2}{|c|}{ Relative stomach volume ${ }^{* 2}$} & $1.78 \pm 0.64$ & $1.89 \pm 0.49$ & $1.94 \pm 0.57$ \\
\hline \multicolumn{2}{|c|}{ Relative intestine length ${ }^{* 3}$} & $0.69 \pm 0.05^{\mathrm{a}}$ & $0.76 \pm 0.05^{b}$ & $0.70 \pm 0.05^{a}$ \\
\hline \multicolumn{2}{|c|}{ Muscle protein $(\mathrm{g})$} & 2.62 & 2.53 & 3.33 \\
\hline \multicolumn{2}{|l|}{ Total lipids $(\mathrm{g})^{*_{4}}$} & 1.70 & 1.61 & 2.43 \\
\hline
\end{tabular}

Values (mean $\pm \mathrm{SD}, n=25$ ) on the same line followed by different superscript letters are significantly different $(p<0.05)$.

$*_{1}$ (Intraperitoneal fat body weight/body weight) $\times 100$.

$*_{2}$ (Stomach volume $(\mathrm{g}) /$ body weight $\left.(\mathrm{g})\right) \times 100$.

*3 Intestine length/body length.

*4 The sum of muscle lipids and IPF lipids.

of group III was higher than in the other groups. HIS was significantly low in the fish fed four times daily with the restricted ration. RSV tended to increase with the supplied amount of diet, but the difference was not significant. RIL was significantly longer in group II in response to feeding regime. Gonads were not found in fish in season.

The effect of feeding regime was assessed using serological parameters, as shown in Table 3. A significant difference was found only in the serum glucose level. Group I showed a significantly lower glucose level than group III. The value of group II showed a mid level between groups I and III. NEFA levels showed similar tendencies to glucose levels.

Table 4 shows hepatic enzyme activities. Group II showed the highest activities in glucose-6-phosphatase and alanine aminoacyl transaminase. The activities of pyruvate kinase, glucose-6-phosphate dehydrokinase, and NADPmalate dehydrogenase tended to be higher in group III. However, these activities were not significantly influenced by feeding frequency and rations.

After the feeding experiment, the fish were kept in the ponds without feeding for 23 days. This starvation resulted in the highest mortality and body weight loss in group 
Table 3. Effect of feeding regime on serological parameters

\begin{tabular}{lcccc} 
& & \multicolumn{3}{c}{ Experimental group } \\
\cline { 3 - 5 } & $n$ & I & II & III \\
\hline Hematocrit (\%) & 20 & $45.8 \pm 7.7$ & $46.2 \pm 6.0$ & $51.0 \pm 8.2$ \\
Total protein $(\mathrm{g} / 100 \mathrm{~m} l)$ & 5 & $0.76 \pm 0.01$ & $0.73 \pm 0.12$ & $0.74 \pm 0.01$ \\
Total lipid $(\mathrm{g} / 100 \mathrm{~m} l)$ & 5 & $1.68 \pm 0.38$ & $1.73 \pm 0.36$ & $1.76 \pm 0.25$ \\
NEFA (mEq $/ l)^{*}$ & 5 & $1.39 \pm 0.24$ & $1.78 \pm 0.35$ & $1.89 \pm 0.37$ \\
Triglycerides $(\mathrm{mg} / 100 \mathrm{~m} l)$ & 5 & $389 \pm 133$ & $352 \pm 74$ & $355 \pm 42$ \\
Phospholipids $(\mathrm{mg} / 100 \mathrm{~m} l)$ & 5 & $802 \pm 184$ & $853 \pm 177$ & $871 \pm 123$ \\
Glucose $(\mathrm{mg} / 100 \mathrm{~m} l)$ & 5 & $27.6 \pm 19.7^{\mathrm{a}}$ & $46.8 \pm 14.0^{\mathrm{a}, \mathrm{b}}$ & $67.8 \pm 26.8^{\mathrm{b}}$ \\
\hline
\end{tabular}

* Nonesterified fatty acids

Values (mean $\pm \mathrm{SD}$ ) on the same line followed by different superscript letters are significantly different $(p<0.05)$.

Table 4. Effect of feeding regime on hepatic enzyme activities*

\begin{tabular}{|c|c|c|c|}
\hline & \multicolumn{3}{|c|}{ Experimental group } \\
\hline & I & II & III \\
\hline Glucose-6-phosphatase & $3.7 \pm 0.2^{\mathrm{a}}$ & $4.6 \pm 0.1^{c}$ & $4.3 \pm 0.1^{b}$ \\
\hline Pyruvate kinase & $12.1 \pm 6.0$ & $13.7 \pm 3.3$ & $17.2 \pm 9.4$ \\
\hline Glucose-6-phosphate dehydrogenase & $59.7 \pm 17.5$ & $68.5 \pm 11.7$ & $75.9 \pm 3.7$ \\
\hline NADP-malate dehydrogenase & $38.9 \pm 4.5$ & $39.8 \pm 7.4$ & $42.7 \pm 3.9$ \\
\hline Arginase & $11.8 \pm 3.1$ & $10.5 \pm 2.8$ & $10.6 \pm 2.2$ \\
\hline Alanine aminoacyl transaminase & $3.2 \pm 0.4^{a}$ & $5.3 \pm 0.3^{b}$ & $5.1 \pm 0.8^{b}$ \\
\hline
\end{tabular}

Table 5. Effect of 23-day starvation on biological parameters of ayu fed different feeding regime

\begin{tabular}{lccc}
\hline & \multicolumn{3}{c}{ Experimental group } \\
\cline { 2 - 4 } & I & II & III \\
\hline Mortality (\%) & 8.5 & 2.8 & 19.7 \\
Mean body weight (g) & $27.2 \pm 3.9^{\mathrm{a}, \mathrm{b}}$ & $24.3 \pm 4.1^{\mathrm{a}}$ & $30.0 \pm 8.9^{\mathrm{b}}$ \\
Body weight loss (\%) & 7.3 & 5.7 & 10.5 \\
Muscle ratio (\%) & $45.6 \pm 3.6$ & $44.0 \pm 4.6$ & $43.7 \pm 5.4$ \\
Muscle protein $(\mathrm{g})$ & 1.96 & 1.83 & 2.34 \\
Muscle protein loss $(\%)$ & 25.2 & 27.7 & 29.7 \\
IPF ratio $(\%)^{*_{1}}$ & $4.15 \pm 1.45$ & $4.12 \pm 1.77$ & $4.73 \pm 2.33$ \\
Total lipids $(\mathrm{g})^{*_{2}}$ & 1.70 & 1.31 & 1.85 \\
Lipid reserve loss $(\%)^{*_{3}}$ & 0 & 18.6 & 23.9 \\
\hline
\end{tabular}

Values (mean $\pm \mathrm{SD}, n=20$ ) on the same line followed by different superscrip letters are significantly different $(p<0.05)$.

${ }^{*}$ (Intraperitoneal fat body weight/ body weight) $\times 100$.

$*_{2}$ Total of muscle lipids and IPF lipids.

${ }^{*}$ Calculated from the sum of muscle lipids and intraperitoneal fat before and after starvation.

III (Table 5). Group II showed the lowest mortality and lowest body weight loss. Body weight loss of group III was more than $10 \%$, while that of group II was only $5.7 \%$. Lipid reserves were expressed as total lipids of the muscle lipid and intraperitoneal fat body lipid. The muscle protein was markedly consumed in all groups, but there was a remarkable difference in exhaustion of the lipid reserves. While group III consumed $23.9 \%$ of the lipid reserves, group I lipids remained constant.

\section{Discussion}

The amount of food consumed by the fish fed to satiation was raised by increasing feeding frequency. In general, high rations induced high body weight gain, but was simultaneously accompanied by high lipid accumulation, ${ }^{9,21,22)}$ This experiment showed that high rations apparently induced high body weight gain, but did not give a significant increase in muscle ratio. The increasing feeding level accelerates growth, but results in a decrease in energy and protein utilization. ${ }^{23)}$ Feed conversion efficiency and the protein efficiency ratio of the group fed to satiation four times daily were not significantly higher than that of the fish fed the restricted diet. Feeding restricted diets results in aggression within fish populations and consequently raises high size variation. The results of the experiments showed high variation in fully fed groups, indicating that variable food intakes occurred within the group. The growth was less variable in the group fed the restricted diet.

Morphological adaptation of the digestive tract, including extended intestine and enlarged intestine surface could be the result of the need for effective utilization of restricted food. ${ }^{24)}$ The short intestine caused by high ration might be due to the unnecessary increase in storage capacity and evacuation time of food. Assuming that an excessive food supply prevents the growth of intestine, food might pass through the gut faster and might be wasted. Intestine length is a phenotypic characteristic, but variable in response to feeding regime. ${ }^{25,26}$ Studies of feeding regimes have shown that long intestine occurred under adequate feeding frequency. ${ }^{4}$ ) The intestine length of ayu fed four times daily with restricted ration was longer than in the other feeding regime groups. Relative intestine length of wild ayu caught in the Ohta river was between 0.7 to 0.9 (unpublished data). Intestine of the fish in this experiment was clearly shorter $(<0.7)$ than that of wild ayu. The long intestine of fish fed four times daily, longer than that of than the other groups, might be caused by a necessary increase in storage capacity for restricted food. Intestine length of artificially produced black sea bream Acanthopagrus schlegeli, was shorter than that of wild fish. ${ }^{27)}$ However, the fish could be elongated within one month after release into the natural environment. ${ }^{28)}$ The digestive tracts appear to be highly responsive to feeding regime and feed organism. ${ }^{29)}$

Hematocrit, total serum protein, as parameters for physiological condition, did not show significant difference among the groups. Serum lipids (total lipid, nonesterified fatty acids, triglycerides, and phospholipids) as indices of lipid metabolism tended to be higher in the groups fed four times daily. The highest glucose level was found in the fish satiated four times daily. The serum glucose level increased with increased feeding rate. ${ }^{9,21)}$ Excessive serum glucose stimulates lipogenesis by stimulating insulin secretion which increases incorporation of glucose into fatty acids. A high glucose level consequently induces high lipid deposition.

As the activity of glucose-6-phosphate dehydrogenase correlates to lipid accumulation and high food intake, ${ }^{4)}$ the high activity found in the fish satiated four times daily 
seemed to activate lipogenesis. Walzem et $a l{ }^{30)}$ showed linear relation between liver enzyme activities (glucose 6-phosphate dehydrogenase and NADP-malate dehydrogenease) and growth in rainbow trout. They are involves in the conversion into NADP and the basis for growth. Activities of glucose-6-phosphate dehydrogenase and NADP-malate dehydrogenase seemed to increase as food intake increased. Activity of glucose-6-phosphatase was significantly higher in the fish fed the restricted diet. The high activity of glucose-6-phosphatase which involved a role in the final stage of gluco-neogenesis might indicate that frequent feeding accelerates gluconeogenesis. The activity of pyruvate kinase which is one of the limiting enzymes in the glycolytic pathway was not influenced. High activity of alanine aminoacyl transaminase was found in the group fed four times daily with restricted diet. The same phenomenon was also found in the best feeding regime in red sea bream. ${ }^{4)}$

Fish metabolism is influenced by feeding regime and dietary composition. Excessive dietary lipids and overfeeding induce high lipid accumulation in the muscle and adipose tissue. The utilization pattern of body constituents during starvation is dependent on the rearing conditions. ${ }^{(-3)}$ The lipid reserves accumulated under inadequate nutritional balance or ration size could not be mobilized as energy sources in response to various energy demands. ${ }^{31-34)}$ The fish reared under adequate rearing conditions could accumulate surplus energy as an energy storage which could be mobilized for energy under demand conditions. Consequently, body weight loss could be minimized due to preferential mobilization of reserved lipids prior to protein degradation. Body weight loss of group II was not markedly different from group I, but higher mortality during starvation would be explained to be due to low mobility of the reserved energy as an energy source. Generally, fish can resist prolonged starvation and respond to starvation in a way that lipid reserves are drawn before the protein is utilized. ${ }^{35)}$ Mortality is not induced by starvation under the normal physiological condition.

The high mortality and high body weight loss during starvation found in this experiment suggested that satiation with four daily feedings did not always induce good physiological conditions. Satiation might occasionally account for nutritional requirements. Previous studies on the feeding frequency of ayu showed that four daily feedings with restricted diets resulted in better growth performance and physiological conditions than one or two daily satiation feedings. ${ }^{2)}$ In addition, lipid metabolism such as lipogenesis and lipolysis could be well regulated under the adequate feeding regime. However, six daily feedings with a restricted diet were not superior to the four daily feedings in growth performance and physiological parameters (Nakagawa, unpublished data). Food provided by four daily feedings with restricted diet might be effectively utilized for growth and energy sources.

The fish fed four times with restricted ration gave better results in responses to growth and starvation than fully fed groups, suggesting that food should be restricted to a certain extent for good growth performance and beneficial food utilization. Therefore, further research is needed to determine adequate rations on growth performance and other measures regarding fish quality and physiological conditions.

Acknowledgments We wish to thank Riken Vitamin Co. Ltd. for supplying Alaskan pollack liver oil.

\section{References}

1) H. Nakagawa: Usefulness of Chlorella-extract for improvement of the physiological condition of cultured ayu, Plecoglossus altivelis (Pisces). Tethys, 11, 328-334 (1985).

2) S.-J. Yao, T. Umino, and H. Nakagawa: Effect of feeding frequency on lipid accumulation in ayu. Fisheries Sci., 60, 667-671 (1994).

3) H. Nakagawa, H. Nishino, Gh. R. Nematipour, S. Ohya, T. Shimizu, Y. Horikawa, and S. Yamamoto: Effects of water velocities on lipid reserves in ayu. Nippon Suisan Gakkaishi, 57, 17371741 (1991)

4) H. Nakagawa, T. Takeda, T. Umino, Md. G. Mustafa, and H. Yamashita: Effect of feeding regime on biometric parameter and hepatic enzyme activities of young red sea bream, Pagrus major. J. Fac. Appl. Bio. Sci., Hiroshima Univ., 34, 167-178 (1995).

5) S. Kayano, S.-J. Yao, S. Yamamoto, and H. Nakagawa: Effects of feeding frequency on the growth and body constituents of young red-spotted grouper, Epinephelus akaara. Aquaculture, 110, 271278 (1993).

6) E. O. Aristizabal Abud: Effect of feeding frequency in juvenile croaker, Micropogonias furnieri (Desmarest) (Pisces: Sciaenidae). J. Fish Biol., 37, 987-988 (1990).

7) E. H. Jorgensen and M. Jobling: Feeding behaviour and effect of feeding regime on growth of Atlantic salmon, Salmo salar. Aquaculture, 101, 135-146 (1992).

8) C. D. Webster, J. H. Tidwell, and D. H. Yancey: Effect of protein level and feeding frequency on growth and body composition of cage-reared channel catfish. Prog. Fish-Cult., 54, 92-96 (1992).

9) S. S. O. Hung, F. S. Conte, and E. F. Hallen: Effects of feeding rates on growth, body composition and nutrient metabolism in striped bass (Morone saxatilis) fingerings. Aquaculture, 112, 349361 (1993).

10) B. J. Buurma and J. S. Diana: effects of feeding frequency and handling on growth and mortality of cultured walking catfish Clarias fuscus. J. World Aquacult. Soc., 25, 175-182 (1994).

11) Y. Cui: growth performance of juvenile white sturgeon as affected by feeding regimen, Prog. Fish-Cult., 59, 31-35 (1997).

12) S. J.S. Johanssen and M. Jobling: The influence of feeding regime on growth and slaughter traits of cage-reared Atlantic salmon. Aquaculture International, 6, 1-17 (1998).

13) J. Koskela, J. Pirhonen, and M. Jobling: Food intake, growth rate and body composition of juvenile Baltic salmon exposed to different constant temperature. Aquaculture International, 5, 351-360 (1997).

14) I. Kubo: Stomach volume of Japanese spiny lobster, Panulinus japonicus. Nippon Suisan Gakkaishi, 27, 1063-1065 (1961).

15) E. G. Bligh and W. J. Dyer: A rapid method of total lipid extraction and purification. Can. J. Biochem. Physiol., 37, 911-917 (1959).

16) G. E. Glock and P. Mclean: Further studies on the properties and assay of glucose-6-phosphogluconate dehydrogenase in rat liver. Biochem. J., 55, 400-408 (1953).

17) T. W. Moon and I. A. Johnston: Starvation and activities of glycolytic and glyconeogenic enzymes in skeletal muscle and liver of the plaice, Pleuronecties platessa. J. Comp. Physiol., 136, 31-38 (1980).

18) S. Ochoa: A "Maric" enzyme from pigeon liver and wheat germ. Method in Enzymol., 1, 739-741 (1955).

19) M. K. Shwartz: Clinical aspects of arginase, Method in Enzymol., 17B, 857-861 (1971).

20) Y. Shimizu, T. Onishi, and S. Murayama: Biochemical studies on wintering of cultured carp-VI. Changes of vitamin $B_{2}$ content, amylase activity and GPT (Glutamic-pyruvic transaminase) activity in liver. Bull. Tokai Reg. Fish. Res. Lab., 59, 65-73 (1969).

21) T. Storebakken, S. S. O. Hung, C. C. Calvert, and E. M. 
Plisetskaya: Nutrient partitioning in rainbow trout at different feeding rates. Aquaculture, 96, 191-203 (1991).

22) I. Soccarato, G. Benatti, M. L. Bianchini, M. Boccignone, A. Conti, R. Napolitano, and G. B. Palmegiano: Differences in performance, flesh composition and water output quality in relation to density and feeding levels in rainbow trout, Oncorhynchus mykiss (Walbaum), farming. Aquaculture and Fisheries Management, 25, 639-647 (1994).

23) E. A. Omar and K. D. Günter: The optimum feeding levels for growing of mirror carp (Cyprinus carpio L.) in intensive culture. $J$. Am. Physiol. Anim. Nutr., 57, 180-190 (1987).

24) R. Hoffer: Morphological adaptation of the digestive tract of tropical cyprinids and cichlids to diet. J. Fish Biol., 33, 399-408 (1988).

25) K. Dabrowsky: Ecological adaptations exist in nutrient requirements of fish: true or false? Comp. Biochem. Physiol., 104A, 579584 (1993).

26 H. W. J. Stroband: Growth and diet dependent structural adaptations of the digestive tract in juvenile grass carp (Ctenopharyngodon idella, Val.). J. Fish Biol., 11, 167-174 (1977).

27) H. Yamashita, T. Umino, S. Nakahara, K. Okada, and H. Nakagawa: Comparison of biochemical characteristics between hatchery-produced and wild black sea bream. Nippon Suisan Gakkaishi, 62, 89-93 (1996).

28) H. Yamashita, T. Umino, S. Nakahara, K. Okada, and H.
Nakagawa: Changes in some properties of black sea bream released into the Daiô Bay, Hiroshima. Fisheries Sci., 63, 267-271 (1997).

29) W. L. Montgomery and P. E. Pollak: Gut anatomy and $\mathrm{pH}$ in a red sea surgeonfish, Acanthurus nigrofuscus. Mar. Ecol. Prog. Ser., 44, 7-13 (1988).

30) R. L. Walzem, T. Storebakken, S. S. O. Hung, and R. J. Hansen: Relationship between growth and selected liver enzyme activities of individual rainbow trout. $J$. Nutri., 121, 1090-1098 (1991).

31) S. Sakamoto and Y. Yone: Effect of dietary phosphorus level on chemical composition of red sea brearn. Nippon Suisan Gakkaishi, 44, 227-229 (1978).

32) M. Takeuchi and J. Nakazoe: Effect of dietary phosphorus on lipid content and its composition in carp. Nippon Suisan Gakkaishi, 47, 347-352 (1981).

33) H. Nakagawa, S. Kasahara, A. Tsujimura, and K. Akira: Changes of body composition during starvation in Chlorella-extract fed ayu. Nippon Suisan Gakkaishi, 50, 665-671 (1984).

34) H. Nakagawa, S. Kasahara, and T. Sugiyama: Effect of Ulva mea supplementation on lipid metabolism of black sea bream, Acanthopagrus schlegeli (Bleeker). Aquaculture, 62, 109-121 (1987).

35) R. M. Love: Feeding and starvation, in "The Chemical Biology of Fishes", Vol. 2, (ed. by R. M. Love), Academic Press, London, 1980, pp. 133-229. 